\title{
LCA in New Zealand
}

\author{
Barbara Nebel
}

Received: 2 May 2011 / Accepted: 2 May 2011 / Published online: 17 May 2011

(C) Springer-Verlag 2011

In 2004, when I started doing LCA work in New Zealand, "LCA" was hardly a known term in New Zealand. A Google search confirmed this and suggested "Light Combat Aircraft", "Lutheran Church of Australia" or "Legalise Cannabis Alliance" as possible explanations.... Things have changed quite a bit since then!

While we admittedly had some catching up to do in terms of adopting Life Cycle approaches, other examples have shown New Zealand to be recognised as a very progressive country, for example, by being the first selfgoverning country in the world to grant all women the right to vote. Some other Kiwi inventions are the electric fence, the disposable syringe, bungee jumping and the first use of a whistle by a referee to end a sporting game.

The pragmatic "Kiwi can do" attitude has helped us to make significant progress, and Life Cycle Management, Life Cycle Assessment and Carbon Footprinting are now well established and progressing very fast in New Zealand.

As Professor Roland Clift commented after his recent visit to New Zealand "I am seriously impressed by the level of activity and professionalism in LCA and Life Cycle Management (LCM) in New Zealand-it is a model to which others might well aspire.... I was struck by the determination of your members to produce practically useful results but remain methodologically rigorous. It's a commendable record."

In this editorial, I would like to provide an overview of the development of Life Cycle Association of New Zealand

\section{B. Nebel $(\square)$}

LCANZ,

11 Rawhiti Road, Pukerua Bay 5026,

Wellington, New Zealand

e-mail: president@lcanz.org.nz

URL: www.lcanz.org.nz
(LCANZ) and its achievements and current activities as well as some notable additional activities in the area of LCA/LCM in New Zealand.

\section{LCA developments in New Zealand}

1996: Anecdotal evidence that the first LCA was completed in New Zealand (confidential).

2004: First fulltime LCA position was established in New Zealand at Scion (then Forest Research).

2005: First LCA workshop was held with about a dozen LCA practitioners from research organisations, universities and consultancies presenting overviews on current projects (Nebel and Nielsen 2005).

2006: At the second LCA workshop, a steering group for LCA in New Zealand was set up with six members from industry, research organisations, academia, consultancy and design (Nebel 2006).

2007: New Zealand's Ministry for Agriculture and Forestry developed "The New Zealand Greenhouse Gas Footprinting Strategy for the Land-Based Primary Sectors".

2008: A Life Cycle Thinking workshop was held by the Ministry for Economic Development and was attended by a wide range of stakeholders from industry, government, research and academia. The informal LCA group was given the mandate to establish the Life Cycle Association of New Zealand.

2009: A Professorship to build New Zealand LCA capabilities was established at Massey University and the associated New Zealand Centre for Life Cycle Management was founded in conjunction with four leading Crown Research Institutes: AgResearch, Landcare New Zealand, Plant and Food, and Scion. 
2009: LCANZ was established in June 2009 to provide a focal point for Life Cycle Assessment and Management work conducted in New Zealand.

2010: First LCA conference in New Zealand with 90 attendees.

\section{Life Cycle Association New Zealand}

LCANZ was established in June 2009 to provide a focal point for Life Cycle Assessment and Management work conducted in New Zealand. This has been supported by an initial grant from the Ministry for Economic Development.

It is our aim to promote networking and knowledge sharing between organisations and people with an interest in Life Cycle Management including assessment. Raising the awareness of Life Cycle Thinking amongst the wider public and business is another key goal of LCANZ. Additionally, we aim to coordinate national activities and to advise policy makers and government on issues relating to Life Cycle Thinking.

LCANZ is an independent special interest group for LCA in New Zealand with a representative membership, including industry, practitioners and researchers. At present, we have 24 corporate, 38 individual and five student members.

\subsection{Objectives of LCANZ}

- Provide coordinated input to the New Zealand government on its policy development for matters relating to $\mathrm{LCA} / \mathrm{LCM}$, with a view to ensuring that government is advised of current work and the views of LCA practitioners

- Identify, prioritise and address barriers to widespread uptake of LCA/LCM, including:

$\circ$ gaps in NZ LCA/LCM expertise

$\circ$ gaps in data

- Provide input into relevant standards and guidelines (national and international), where it is deemed appropriate to do so

- Review whether there is a need for professional recognition of LCA/LCM practitioners

- Facilitate access to relevant LCA/LCM experts in New Zealand

- Periodically review the need for LCA/LCM resources, and where a need is identified, facilitate the development of its/their production

- Provide technical advice on LCA/LCM work, where appropriate and feasible
Specific areas of activities are currently around a New Zealand Life Cycle Inventory database, driving best practice, and networking and communication. Three working groups have been established and are actively pushing these areas. In addition to this, we are preparing for the 2nd LCA conference in New Zealand for Autumn 2012 (N.B. this is March/April for our northern hemisphere readers).

A short overview of the working groups and the first LCA conference is provided here:

\subsection{Networking and communication working group}

A networking and communication subcommittee has been established with the objective of increasing the uptake of LCA/LCM. This is to be achieved by communicating at both a practitioner level, as well to those that would benefit from using LCA/LCM. The first step has been the establishment of a website, www.lcanz.org.nz, which includes a wide range of case studies. Three networking events have been held in the first year. These were video linked to four sites and included presentations, but more importantly informal discussions over a drink. These events were in addition to our extremely successful inaugural conference that was held in March 2010 and will now run in the alternate year to the Australian LCA conference.

\subsection{LCI working group}

A need for the development of New Zealand-specific inventory datasets has been identified by those involved in LCA and carbon footprinting projects in New Zealand over the last few years. The inventory working group was therefore the first LCANZ Working Group formed after establishment of LCANZ. Its focus is the development of robust and transparent New Zealand datasets for use in LCA studies. The first milestone of this working group was the adoption of the following resolution by LCANZ members after extensive consultation with stakeholders:

"That the ILCD Handbook data format be adopted as the current preferred format for the NZ Life Cycle Inventory Database, subject to confirmation through the proposed LCI Feasibility Study".

This feasibility study is currently being undertaken; it involves the development of a project proposal detailing the work required for the development of an operational database, supporting review process and ongoing maintenance.

\subsection{Best practice working group}

The best practice and a high standard of quality of LCA including carbon footprinting studies are essential for 
credibility of the tools. However, LCA results also need to be applied and interpreted appropriately. This aspect of the strategy therefore includes not only the studies themselves, but also the use of the results. A best practice working group is therefore currently providing input to the LCANZ committee on LCA methodological issues. The working group has 17 members, including some from the Australian Life Cycle Association. Examples to date include the description of the major impact categories and their relevance to New Zealand and a paper on the use of weighting in LCA and if it is possible with current New Zealand data.

\subsection{First NZ LCA conference}

"Bridging the Gap between Tools and Practice" was the title of the first LCA conference in New Zealand, jointly organised by LCANZ and the New Zealand Life Cycle Management Centre (NZLCM) Centre.

Judging from the feedback of the nearly 90 participants, mainly from New Zealand and also from Norway, Austria, UK and of course, Australia, the conference achieved its goal in contributing to closing the gap between tools and practice. Feedback from the conference indicated that people particularly appreciated:

- "The casual, social, friendly attitude. Respectful discussions that look forward and drive the LCA industry forums."

- "Relaxed atmosphere. No politics. Common cause."

- "Meeting a wide variety of people-researchers, consultants, businesses - all interested in the same subject!"

- "Discovering that representatives from competing products were equally frustrated with throwing stones at each other on environmental claims."

The organisers were particularly impressed with the number of people at the conference who were really interested and knowledgeable in the area of LCA, and who engaged in the discussions about methodology, application and the direction of LCA in New Zealand.

\section{Other LCA activities in New Zealand}

\subsection{New Zealand life cycle management centre}

The New Zealand Life Cycle Management Centre, founded in 2009 with an initial funding from the Ministry of Agriculture and Forestry, is a partnership between Massey University and four Crown Research Institutes: AgResearch, Landcare Research, Plant \& Food Research and Scion Research. Its mission is to build capability for LCM, including
LCA, in New Zealand. The Centre partners work together to provide education, training and research in the assessment and management of product and service life cycles. Two postgraduate papers in Life Cycle Assessment have been developed and are offered at Massey University to students wanting to specialise in Life Cycle Assessment and Management at Postgraduate Diploma or Master's level; additional Continuing Professional Development courses are available for those who want to gain a better understanding of LCA, and/or commission and manage LCA studies undertaken by consultants. Technical Workshops are held on topical issues (such as Water Footprinting), and a Working Paper Series is under development. Events are organised under the Food for Thought Programme; they have included a Business Forum on "Future Footprints: Sustainability in the Marketplace" attended by 125 people, a Policy Roundtable on Sustainability involving senior government policymakers, and a series of seminars involving three international speakers: Professor Roland Clift from the University of Surrey, UK; Dr Alan Knight, a Sustainability Consultant advising the Department for Environment, Food and Rural Affairs (DEFRA) and others in the UK; and Katherine Jennrich who is responsible for the Supply Chain Greenhouse Gas Innovation Program at Walmart, USA. The Centre partners with LCANZ for the biennial Life Cycle Assessment Conference, and other events as appropriate.

More details about the Centre can be found at: http:// www.lcm.org.nz/

\subsection{Establishing GHG footprints for the primary sector}

New Zealand's Ministry for Agriculture and Forestry developed "The New Zealand Greenhouse Gas Footprinting Strategy for the Land-Based Primary Sectors" at the end of 2007.

The strategy seeks to help New Zealand's primary sectors respond to significant and increasing pressure by key export markets for information on the GHG-intensity of their products.

A sector approach has been applied as part of this strategy and carbon footprinting projects undertaken represent over $80 \%$ of New Zealand's primary sector exports. They include for example various fruits sectors, dairy, forestry, meat production, wool, some vegetables. Also underway are tech transfer projects.

These projects provide a standardised way for measuring and managing GHG emissions across the life cycle of a product. The aim is to help sectors measure, manage and mitigate GHG emissions across the supply chain.

For further information see:

http:/www.maf.govt.nz/environment-natural-resources/ climate-change/greenhouse-gas-footprinting-strategy 


\section{Outlook}

The LCA sector in New Zealand has developed rapidly over the last few years. While we are establishing our "Kiwiidentity" to provide a domestic focus point for stakeholders in New Zealand we are also very much interested in developing strong links with the international LCA community. As part of this we have, for example, agreed a Memorandum of Understanding to collaborate with our colleagues across the Tasman, the Australian Life Cycle Association and are exploring the best way to be part of the ILCD data network.
Acknowledgement I would like to thank Sarah McLaren, Andrew Barber and Kimberly Robertson for their contributions to this editorial.

\section{References}

Nebel B (2006) Second LCA Workshop/Roundtable, Rotorua, Scion, NZ, February 2006. Int J LCA 11(4):292-293

Nebel B, Nielsen PS (2005) LCA Workshop/Roundtable, Rotorua, Forest Research, NZ, February 2005. Int J LCA 10(5):375-376 